\title{
Consentimento Informado na Pesquisa Clínica: Teoria e Prática
}

\author{
Informed Consent in a Clinical Trial: Theory and Practice
}

Ellen Hardy, Silvana Ferreira Bento, Maria José Duarte Osis, Eliana Maria Hebling

\section{RESUMO}

Objetivo: avaliar a concordância entre a teoria sobre consentimento informado, representada pela Resolução 01/88, e a prática de sua obtenção de acordo com o relato de pesquisadores e de mulheres que participaram de suas pesquisas.

Métodos: onze pesquisadores de três centros de excelência em pesquisa sobre regulação da fecundidade e 18 mulheres, sujeitos de suas pesquisas. A informação foi obtida por meio de entrevistas em profundidade e foi realizada análise de conteúdo.

Resultados: o relato dos pesquisadores estava de acordo com as exigências da Resolução, entretanto, o relato das mulheres mostrou que a maioria dos tópicos exigidos não foi tratada com elas quando convidadas para a pesquisa.

Conclusão: observou-se discordância entre teoria e prática em obter o consentimento. Isto pode dever-se a dificuldades no cumprimento das exigências da Resolução então em vigor. Por outro lado, também é possivel pensar em dificuldades dos pesquisadores para abordar as mulheres e/ou que elas tenham esquecido as informações recebidas. Finalmente, a obtenção do consentimento dos pesquisadores e das mulheres para participarem neste estudo pode ter colaborado para a ocorrência desta discordância.

PALAVRAS-CHAVE: Consentimento informado. Bioética. Investigação clínica.

\section{Introdução}

O primeiro documento brasileiro, identificado pelas autoras, abordando a questão do consentimento informado em pesquisas com seres humanos data de 1978. Naquele ano, a Câmara Técnica de Medicamentos publicou a Resolução Normativa $1 / 78^{1}$, dispondo que "para as pesquisas terapêuticas, segundo o critério do pesquisador, o consentimento do paciente poderá ser obtido de modo verbal ou por escrito, quando julgado conveniente". Em 1981, a Divisão Nacional de Vigilância Sanitária de Medicamentos (DIMED), considerando os riscos envolvidos em novos procedimentos terapêuticos, os deveres éticos por parte de médicos e laboratórios produtores de novos medicamentos e os medicamentos importados não submetidos ao seu controle de qualidade, publicou a Portaria No. $16^{2}$. Esse foi o primeiro docu-

Centro de Pesquisas Materno-Infantis de Campinas (Cemicamp)

Correspondência:

Ellen Hardy

Caixa Postal 6181

13081-970 - Campinas - SP

Apoio financeiro da Organização Mundial da Saúde (OMS) mento brasileiro que apresentou um "texto mínimo a ser contido no Termo de Conhecimento de Risco e que deverá ser lido e/ou informado ao paciente ou seu responsável". Novo documento foi publicado em 1988 pelo Conselho Nacional de Saúde, com o objetivo de normatizar a pesquisa na área de saúde. A Resolução $01 / 88^{3}$ define o consentimento pós-informação como "o acordo por escrito mediante o qual o indivíduo, objeto da pesquisa ou, se for o caso, seu representante legal, autoriza sua participação na pesquisa, com pleno conhecimento da natureza dos procedimentos e riscos a que se submeterá, com a capacidade de livre arbítrio e sem qualquer coação".

O Artigo 11, Capítulo 2 do referido documento dispõe que o sujeito da pesquisa, ou se for o caso seu representante legal, deverá receber explicação clara e completa, de forma a compreender seu objetivo e justificativa, os procedimentos que serão utilizados, os possiveis desconfortos, riscos e benefícios esperados. Essa explicação também deve abordar outros itens, como procedimentos alternativos, garantia de esclarecimento de dúvidas, liberdade de retirar o consentimento a qualquer momento e sem qualquer prejuizo, a segurança de sigilo e privacidade. Além disso, deverá 
ser ressaltado o compromisso de proporcionar informação atualizada sobre o estudo, disponibilizar tratamento médico e indenização em caso de danos causados pela pesquisa e de cobertura de gastos adicionais.

A existência desses documentos não parece ter satisfeito as necessidades da sociedade quanto aos aspectos éticos envolvidos nas pesquisas com seres humanos, pois no final da década de 80 e na primeira metade dos anos 90, o debate sobre os possiveis abusos nessa área esteve sempre presente. A impressão que se tem, ao revisar a literatura pertinente, é que provavelmente esses documentos não foram suficientemente disseminados e, como conseqüência, poderiam ter sido ignorados pelos pesquisadores em geral. Evidência disso foi a mobilização de grupos organizados de mulheres em defesa dos direitos reprodutivos. O principal argumento de tais grupos era de que os pesquisadores que trabalhavam em regulação da fecundidade tiravam vantagem das mulheres que eram pobres, ignorantes sobre o assunto estudado, que não tinham poder para argüir e fazer perguntas, e que acabavam assinando formas de consentimento informado na base da confiança ${ }^{4}$. Pesquisas clínicas com contraceptivos foram conduzidas tanto em países desenvolvidos como em desenvolvimento, mas quando se utilizavam novas drogas, elas eram testadas primeiramente nos países em desenvolvimento, com pessoas pobres, sem instrução e sem o seu consentimento $^{5}$. Além disso, a mídia expressouse mediante diversos artigos publicados nos jornais de todo o Brasil ${ }^{6-9}$, que enfocavam a desinformação, a pobreza e a falta de instrução como características das mulheres que participavam como sujeitos de pesquisas com contraceptivos. Esses fatos parecem ter guiado os grupos organizados de mulheres para a participação efetiva em comissões ministeriais e campanhas "contra os abusos à integridade das mulheres, detectados nos serviços de planejamento familiar e na ação de médicos e cientistas responsáveis por novas tecnologias contraceptivas"4.

Apesar desse debate, não se encontraram na literatura estudos que avaliassem a situação do consentimento informado requerido em pesquisas clínicas com seres humanos, na área de regulação de fecundidade. Por isso, considerou-se necessário conhecer a experiência brasileira com o consentimento informado nessa área. O presente trabalho tem como objetivo avaliar a concordância entre a teoria sobre consentimento informado, representada pelas disposições da Resolução $01 / 88$, e a prática de sua obtenção, de acordo com o relato de pesquisadores e de mulheres que participaram de suas pesquisas.

\section{Pacientes e Métodos}

Em 1997 foi desenvolvido estudo qualitativo em três centros de excelência em pesquisas na área de regulação da fecundidade, localizados nas regiões Sul, Sudeste e Nordeste do Brasil. O protocolo da pesquisa foi aprovado pela Comissão de Ética Médica do Hospital das Clínicas da UNICAMP.

Para a coleta dos dados, os primeiros contatos foram feitos com o diretor de cada Centro para convidar a instituição a participar deste estudo. Após aceitar o convite, cada diretor indicou uma pesquisa que estava em andamento ou havia sido finalizada nos doze meses anteriores, os pesquisadores envolvidos nessa pesquisa e algumas mulheres que haviam sido seus sujeitos. Cada uma dessas pesquisas havia implicado/implicava o uso de um contraceptivo diferente. Foi obtido o consentimento informado individual dos diretores, pesquisadores e das mulheres por meio de um processo que envolveu a informação sobre o estudo, solução de dúvidas e assinatura do Termo de Consentimento por cada um dos participantes. Todos eles receberam uma cópia desse documento.

As informações foram obtidas por meio de entrevistas em profundidade, com roteiros elaborados para cada categoria de participante. Os roteiros foram baseados em itens selecionados do artigo 11 da Resolução $01 / 88$. No total, foram entrevistados 11 pesquisadores, incluindo os três diretores que também eram pesquisadores principais das pesquisas indicadas, e 18 mulheres. As entrevistas foram individuais, gravadas mediante autorização dos participantes e identificadas apenas por um número. Os pesquisadores foram entrevistados no próprio Centro onde trabalhavam e as mulheres no hotel onde as pesquisadoras estavam hospedadas. Esta estratégia facilitou a abordagem dos sujeitos deste estudo, permitindo economia de tempo aos pesquisadores e privacidade às mulheres para o relato de suas experiências como sujeitos de pesquisas.

Para o processamento e análise dos dados, todas as entrevistas foram transcritas na sua integra e a transcrição sempre foi revisada por uma pessoa distinta da que transcreveu. A seguir, as transcrições foram lidas a partir de uma lista das variáveis que compunham cada roteiro, para a identificação e codificação das falas dos sujeitos. Este trabalho de codificação foi realizado por duas profissionais, em diferentes momentos, após a leitura das transcrições. Quando ocorria alguma discordância, o consenso era obtido por meio de discussão do caso entre as duas. A etapa seguinte consistiu em resumir as respostas para cada variável, em cada Centro. Esse resumo foi revisado 
por uma das autoras (EH). Concluídas essas análises parciais, foi elaborado resumo geral, por variável, incluindo todos os Centros. Esse processo de análise foi orientado pelas propostas metodológicas de Wolcott ${ }^{10}$.

Para este trabalho os dados foram tratados de forma quantitativa. Foi preparada uma freqüência das respostas dos pesquisadores e das mulheres com respeito às informações dadas e recebidas por ocasião da obtenção do consentimento informado ${ }^{11}$.

\section{Resultados}

Na Tabela 1, apresenta-se um resumo do que se observou ao perguntar aos pesquisadores e mulheres sujeitas de pesquisa sobre as informações fornecidas e recebidas por ocasião da obtenção do consentimento informado. De modo geral, quase todos os pesquisadores afirmaram ter fornecido às mulheres as informações requeridas. Os dois itens em que um menor número de pesquisadores referiu ter provido informações foram os "beneficios que se podem obter" (item 6) e que "se existirem gastos adicionais, serão absorvidos pelo orçamento da pesquisa" (item 7).

Tabela 1 - Número de pesquisadores que referiram ter fornecido e de mulheres que disseram ter recebido as informações sobre alguns itens exigidos pela Resolução 01/ 88 para obtenção do consentimento informado

\begin{tabular}{lcc}
\hline Itens exigidos & Pesquisadores & Mulheres \\
\hline Objetivo e justificativa da pesquisa & 10 & 6 \\
$\begin{array}{l}\text { Procedimentos a serem utilizados e seus } \\
\text { propósitos }\end{array}$ & 10 & 10 \\
$\begin{array}{l}\text { Desconfortos e riscos esperados } \\
\text { Benefícios que se podem obter }\end{array}$ & 9 & 8 \\
Garantia de receber respostas a & 10 & 1 \\
qualquer pergunta ou esclarecimento a & & 14 \\
qualquer dúvida & & \\
Liberdade de retirar seu consentimento & 10 & 9 \\
$\begin{array}{l}\text { a qualquer momento, sem que isso traga } \\
\text { prejuízo à continuação de seu cuidado }\end{array}$ & & \\
e tratamento & & \\
$\begin{array}{l}\text { Segurança de que não se identificará o } \\
\text { indivíduo e que se manterá o caráter } \\
\text { confidencial da informação relacionada } \\
\text { com a sua privacidade }\end{array}$ & 10 & \\
$\begin{array}{l}\text { Disponibilidade de tratamento médico } \\
\text { Se existirem gastos adicionais, serão }\end{array}$ & 11 & 12 \\
$\begin{array}{l}\text { absorvidos pelo orçamento da pesquisa } \\
\text { (ressarcimento de despesas dos sujeitos) }\end{array}$ & & \\
N & 11 & \\
\hline
\end{tabular}

Os pesquisadores que referiram terem falado às mulheres sobre os possiveis beneficios citaram informações sobre a possibilidade de fazer exames (ginecológico, Papanicolaou, ultra-som), uma avaliação bioquímica, teste de gravidez caso a menstruação atrasasse e que não teriam que pagar pelo método, além de dizerem que elas estariam participando de uma coisa boa, que seria bom para elas no futuro e que traria beneficios para a humanidade.

Do total de pesquisadores entrevistados, três referiram não terem oferecido nenhuma compensação às mulheres, sete declararam terem oferecido vale transporte e um ofereceu lanche para algumas delas. Um dos pesquisadores disse que não sabia se havia sido oferecido algum tipo de ressarcimento, ao passo que outro mencionou a possibilidade de os sujeitos serem pagos pela participação em pesquisas, embora isso não fosse prática comum no Brasil.

Ao contrário do que ocorreu entre os pesquisadores, as mulheres que haviam sido sujeitos de pesquisas disseram que não haviam recebido informações acerca da maioria dos itens requeridos pela Resolução.

Das dezoito entrevistadas, apenas seis referiram ter recebido informações sobre o objetivo e/ ou a justificativa da pesquisa na qual participaram. Das restantes, uma relatou ter recebido informação acerca desse assunto apenas durante as consultas de acompanhamento. Outra disse que só ficou sabendo que estava participando de uma pesquisa, por acaso, pela recepcionista da clínica.

Quanto aos procedimentos a serem utilizados e seus propósitos, de modo geral, as mulheres disseram que sabiam que deveriam retornar periodicamente à clínica, caso concordassem em participar da pesquisa. Entretanto, não lhes foram fornecidos muitos detalhes sobre o que iria acontecer em cada uma das visitas de seguimento. Dez mulheres relataram que lhes foi dito que deveriam retornar para fazer alguns exames tais como de sangue, de mama, de urina, ginecológico e/ou Papanicolaou, mas não sabiam dizer o porquê de fazê-los. As outras oito referiram não terem recebido informações sobre quais procedimentos seriam utilizados.

Duas mulheres lembravam de terem sido informadas que deveriam comunicar os efeitos colaterais observados, quando fossem às consultas de acompanhamento. Outra relatou que teria que informar ao pessoal da clínica se algo diferente ocorresse enquanto estivesse usando o método, porque nesse caso teria que fazer alguns exames.

Oito mulheres disseram que sabiam que havia risco de engravidar usando o método, porque, como qualquer outro, este também poderia 
falhar, mas que não corriam nenhum risco com a saúde em geral. Apenas uma mulher referiu ter sido informada sobre a possibilidade de reação alérgica e orientada a comunicar a ocorrência ao profissional. Outra disse que não havia sido informada se o método poderia causar mal ou não à sua saúde.

Apenas uma mulher referiu que the haviam falado sobre o beneficio que teria por participar no estudo. Este poderia resultar do fato de o contraceptivo que estava usando prevenir doenças sexualmente transmissiveis. As demais não lembravam de terem recebido nenhuma informação sobre beneficios.

Das dezoito mulheres entrevistadas, catorze disseram terem sido asseguradas de que poderiam esclarecer qualquer dúvida com os profissionais envolvidos na pesquisa. Todavia, três delas responderam que não foi especificada uma determinada pessoa como responsável por responder às dúvidas. Quatro mulheres mencionaram que não lhes foi dito o que fazer se tivessem dúvidas durante sua participação no estudo.

Metade das mulheres (nove) referiu não ter recebido nenhuma informação relacionada à liberdade de decidir não participar ou de descontinuar sua participação em qualquer momento. Quatro disseram que foram informadas de que sua participação no estudo era voluntária e oito que poderiam desistir a qualquer momento. Cinco referiram que o atendimento delas na clínica continuaria, mesmo se deixassem de usar aquele método. Uma das mulheres referiu que, caso ela descontinuasse sua participação, não mais poderia ser atendida na clínica (que era grátis).

A maioria das mulheres (doze) disse não ter recebido nenhuma informação sobre seus nomes aparecerem em algum momento, nem de serem identificadas por outras pessoas como participante da pesquisa. Quatro disseram que foram informadas de que seus nomes não iriam aparecer e duas lembraram que seriam apenas identificadas por números.

Sobre a disponibilidade de tratamento médico, as mulheres declararam que foram informadas sobre a necessidade de retornarem periodicamente à clínica, caso concordassem em participar do estudo. Das dezoito mulheres, doze mencionaram terem sido avisadas sobre qual profissional faria suas consultas de seguimento e seis alegaram que não lhes disseram nada, embora uma destas acreditasse que seria o próprio médico que a havia encaminhado.

Nenhuma das mulheres referiu ter recebido alguma forma de pagamento para participar do estudo. As mulheres, em geral, disseram que não foi oferecido vale para transporte nem lanche. Seis delas referiram que foi oferecido suporte para transporte e lanche, entretanto elas é que teriam que decidir quando iriam precisar, mas não receberam nada. Duas declararam que não lhes foi oferecido qualquer tipo de suporte, ao passo que outra mencionou ter recebido ajuda por um tempo, mas já não estava precisando mais. Outra referiu que haviam lhe ajudado no primeiro dia, quando ela entrou na pesquisa, e que ela não sabia se isso seria oferecido no futuro.

\section{Discussão}

Este estudo mostra um desencontro entre as respostas dos pesquisadores, quanto às informações que foram fornecidas, e das mulheres, quanto às informações recebidas, por ocasião da obtenção do consentimento informado. Isto pode levar a supor que as determinações da Resolução 01/ 88 haviam sido assimiladas no discurso dos pesquisadores, mas não necessariamente levadas em conta quando desenvolviam suas pesquisas. Além disso, é possivel também pensar que o cumprimento das exigências dessa Resolução tenha sido visto como dificil, que tenha havido dificuldades na abordagem das mulheres pelos pesquisadores, que elas tenham esquecido as informações fornecidas, e, finalmente, é necessário considerar a possibilidade de viés decorrente da forma como foi obtido o consentimento dos pesquisadores e das mulheres para participarem em nosso estudo.

A dificuldade na abordagem dos sujeitos pode estar relacionada à diferença no nível educacional e social entre as duas categorias de participantes: praticamente todos os pesquisadores (dez) tinham, no mínimo, o curso superior completo, ao passo que apenas uma mulher havia completado o curso universitário. O diferente nível educacional pode ter-se traduzido na utilização de linguagem pouco accessivel por parte dos pesquisadores e na falta de coragem das mulheres em admitir que não entenderam e pedir esclarecimentos às suas dúvidas. Segundo o Conselho Federal de Medicina, "a relação entre o pesquisador e o sujeito da pesquisa médica guarda estreita e inevitável analogia com a relação médico-paciente"12. A figura do médico, geralmente, expressa a imagem do poder e da detenção do conhecimento, de forma que questionar e/ou contestar as suas falas pode não ser um facilitador da relação pesquisador-sujeito. Também é notório que a linguagem médica é mais técnica do que comum, o que pode favorecer a distância entre aquele que informa e o que recebe a informação, em termos de compreensão e apreensão. 
Além disso, as exigências da Resolução quanto ao conteúdo do Termo são muitas e, para cumpri-las, os pesquisadores acabam escrevendo um documento longo e complexo, que pode não alcançar o objetivo ético do Termo de Consentimento. Segundo Blaney ${ }^{6}$, tal objetivo é proteger a liberdade e a dignidade dos sujeitos da pesquisa, não devendo ser considerado como documento de proteção aos pesquisadores e agências financiadoras e, muito menos, como estratégia de permissividade de procedimentos que ferem a dignidade do sujeito. Nessa perspectiva, o conteúdo do Termo deveria ser definido a partir da visão dos possiveis sujeitos, acerca de qual seria a informação necessária para assegurar que o objetivo fundamental fosse atendido. Isto, porém, esbarra no fato de que documentos como a Resolução 01/88 são impostos verticalmente sobre a sociedade, sem uma discussão com os setores por ele atingidos. Isto significa que também os pesquisadores não devem ter sido consultados na elaboração da Resolução, de maneira que, nem sempre, as exigências desse documento seriam compativeis com a realidade cotidiana dos profissionais.

Cabe ainda considerar a possibilidade de as mulheres nem sempre lembrarem de terem recebido as informações que os pesquisadores afirmaram ter dado, porque não estavam interessadas nessas explicações. Isto já foi observado quando se estudou a associação entre o contraceptivo aceito e a percepção da informação recebida. Número significativo de mulheres que aceitou o dispositivo intra-uterino declarou que não prestou atenção quando lhes foi dada informação sobre o implante subdérmico Norplant ${ }^{13}$. Concomitantemente, mais uma vez, a extensão do Termo, muito detalhado e escrito em linguagem pouco acessivel, pode ter sido outro fator de desinteresse para que as mulheres se esquecessem das informações. Alguns autores ${ }^{5}$ por exemplo, observaram que sujeitos de uma determinada pesquisa, mesmo tendo assinado um Termo de Consentimento, não se lembravam das informações recebidas, e que mais de um quarto deles não estava sequer ciente de sua participação na pesquisa.

Um exemplo das possiveis dificuldades das mulheres para a compreensão e assimilação do conteúdo do Termo foi observado pelas próprias autoras do presente estudo. As mulheres, quando foram convidadas para as entrevistas, tiveram muita dificuldade para ler o Termo, cujo conteúdo já havia sido explicado. Por exemplo, uma delas disse: "Você não poderia ler para mim ou poderiamos ler juntas?" Isto indica que a simples leitura de um documento não é suficiente para garantir que a pessoa assimile as informações de maneira a estar preparada para aceitar parti- cipar de uma pesquisa de forma esclarecida e voluntária.

Uma última possivel explicação para a discordância observada entre a teoria e a prática do consentimento informado, segundo o relato dos pesquisadores e das mulheres, refere-se à possível interferência produzida pela forma como foi obtido o consentimento deles para a participação em nosso estudo. Os pesquisadores deram o consentimento após terem recebido uma explicação, terem assinado o Termo e recebido uma cópia do mesmo. Tudo isso, sem dúvida, pode ter dado a eles algumas sugestões para que suas respostas se enquadrassem no que aparentemente era correto. As mulheres, porém, embora tivessem passado pelo mesmo procedimento para participarem deste estudo, não precisavam mostrar que conheciam a Resolução ou a forma de obter o consentimento. Provavelmente responderam somente o que lembravam. Os resultados apresentados levam a concluir que, por ocasião da realização deste estudo, era possivel levantar uma série de interrogações relacionadas ao processo de obter e dar o consentimento em pesquisas sobre regulação da fecundidade, em pesquisas que envolviam seres humanos e, ao mesmo tempo, sobre o valor ético do mesmo. Estas interrogativas e os problemas provenientes, provavelmente, foram retomados e refletidos pelo Conselho Nacional de Saúde por ocasião da elaboração da Resolução 196/96 ${ }^{14}$, que atualmente dispõe sobre as normas de pesquisa envolvendo seres humanos. Resta saber como esse documento está sendo aplicado pelos pesquisadores e como isso tem se refletido nos sujeitos de pesquisa.

\section{ABSTRACT}

Purpose: to evaluate the agreement between the theory about informed consent, represented by Resolution 01/88, and the practice according to the report of researchers and of women who were subjects of their research.

Methods: eleven researchers from three centers of excellence in research related to fertility regulation in Brazil and 18 women, subjects of their research. Information was obtained through in-depth interviews and content analysis was carried out.

Results: the report of the researchers agreed with the requirements of the Resolution; however, the women's report showed that most of the required items were not referred to when they were invited to participate in the research.

Conclusion: a disagreement was observed between theory and practice in obtaining informed consent. This may be explained by difficulties in complying with the requirements of the Resolution in force at the time. On the other hand, it is 
also possible to imagine difficulties experienced by researchers when approaching the women and/or that the women also forgot the received information. Finally, a bias may have resulted from the researchers and women who had to give consent to participate in this study.

KEY WORDS: Informed consent. Bioethics. Clinical research.

\section{Agradecimentos}

As autores agradecem à Organização Mundial da Saúde pelo apoio financeiro proporcionado, bem como aos pesquisadores e às mulheres que dedicaram seu tempo para responder às nossas questões.

\section{Referências}

1. Brasil. Ministério da Saúde. Conselho Nacional de Saúde. Câmara Técnica de Medicamentos. Resolução Normativa 1/78, de 30 de agosto de 1978. Diário Oficial da República Federativa do Brasil, Brasília, 17 out 1978 . Seção I, pt 1, p. 16746.

2. Brasil. Ministério da Saúde. Secretaria Nacional de Vigilância Sanitária. Divisão Nacional de Vigilância Sanitária de Medicamentos (DIMED). Portaria $\mathrm{n}^{\circ}$ 16, de 27 de novembro de 1981. Diário Oficial da República Federativa do Brasil, Brasília, 17 out 1978. Seção I, p.23745.

3. Brasil. Ministério da Saúde. Conselho Nacional de Saúde. Resolução nº 01/88 de 13 de junho de 1988. Diário Oficial da República Federativa do Brasil, Brasilia, 14 jun 1988. Seção I, p.10713.
4. Pitanguy J. Feminist politics and reproductive rights: the case of Brazil. In: Sen G, Snow RC, editors. Power and Decision. The Social Control of Reproduction. Boston: Harvard School of Public Health; 1994. p.101-22.

5. Blaney CL. Long-acting methods require special care. Network 1994; 15:18-21.

6. Blaney CL. Informed consent plays key role. Network 1994; 15:22-25.

7. Paciente leiga usa cápsula. Jornal do Comércio 29 ago 1986; p.11.

8. Conferência Nacional de Saúde e Direitos da Mulher. Relatório Final. Brasília: Centro de Documentação do Ministério da Saúde; 1987. p.57.

9. O CMB/AM e a esterilização da mulher. Jornal do Comércio 31 ago 1986; p.12.

10.Wolcott HF. Transforming qualitative data: description, analysis, and interpretation. Thousand Oaks: Sage; 1994. p.433.

11.Krippendorff K. Content analysis: an introduction to its methodology. Beverly Hills: Sage; 1990. p.109-18.

12. Marques R. Declaracao de Helsinque. J CFM $2001 ; 16: 6$

13. Hardy E, Goodson P. Association between contraceptive method accepted and perception of information received: a comparison of Norplant and IUD acceptors. Contraception 1991; 43:121-8.

14.Brasil. Ministério da Saúde. Conselho Nacional de Saúde. Normas de pesquisa envolvendo seres humanos. Res. CNS 196/96. Bioética 1996; 4 Suppl:15-25.

Recebido em: 2/4/2002 Aceito com modificações em: 1/8/2002

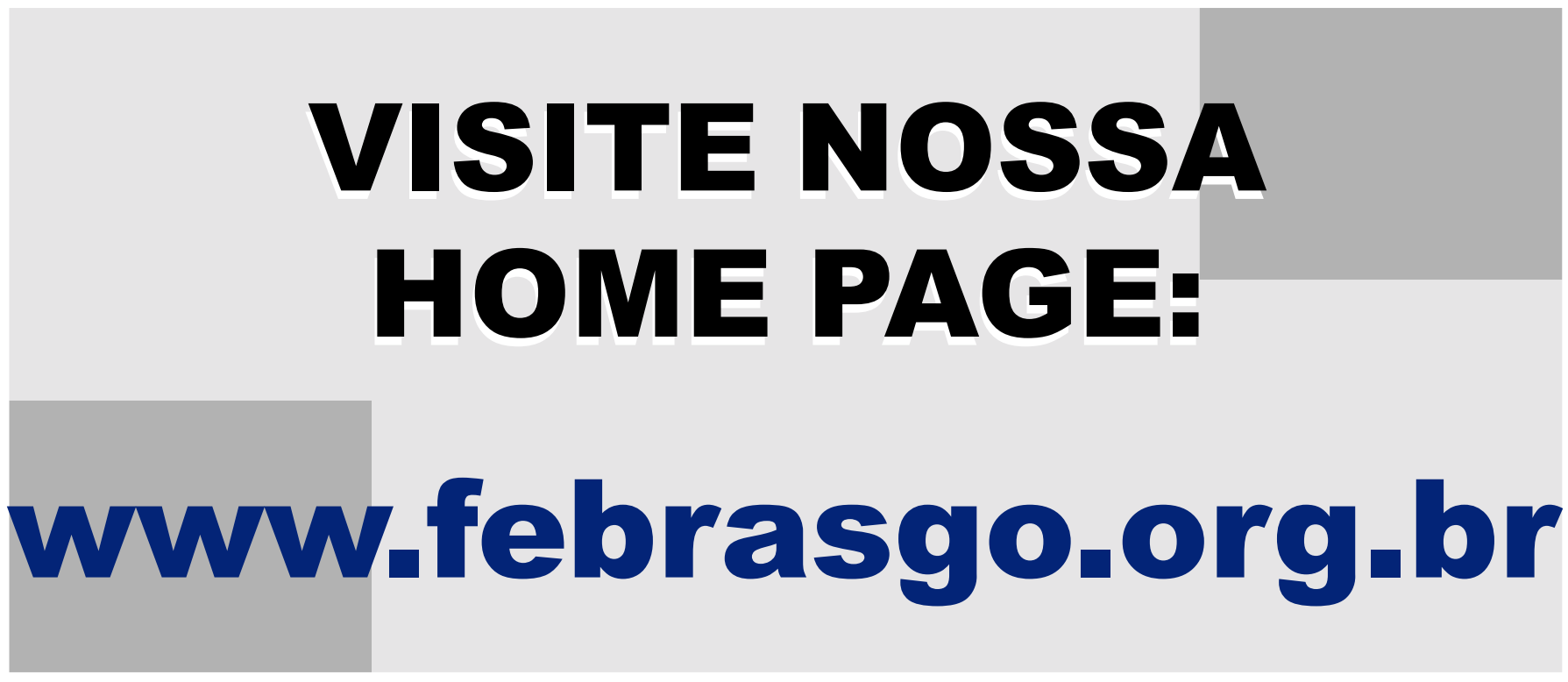

